\title{
Assessing English Teachers as a Foreign Language (EFL) Telecollaborative Competence: A Case Study from Saudi Arabia
}

\author{
Ahmed Abdulateef Al Khateeb ${ }^{1}$ \\ ${ }^{1}$ Department of English Language, College of Arts, King Faisal University, Al-Ahsa, Saudi Arabia \\ Correspondence: Ahmed Abdulateef Al Khateeb, Department of English Language, College of Arts, King Faisal \\ University, Al-Ahsa, Saudi Arabia. E-mail: ahalkhateeb11@gmail.com
}

Received: January 2, 2018 Accepted: March 12, 2018 Online Published: March 14, 2018

doi: $10.5539 /$ elt.v11n4p52 URL: http://doi.org/10.5539/elt.v11n4p52

\begin{abstract}
The role of telecollaborative competence has become vital among twenty-first century English language teachers. Yet, the reinforcement of this competence with its establishment within educational systems is not always straightforward; particularly in traditional educational settings. Looking at telecollaborative competence amongst English as a foreign language (EFL) teachers in relation to region, gender and qualification have become central inquiries within this research. The findings have shown correlation among some elements of telecollaborative competence as shown in Tables 1-6. In line with these findings, some recommendations, and future research directions have been suggested.
\end{abstract}

Keywords: telecollaboration, EFL teachers, competence, experience, willingness

\section{Introduction}

The impetus of this research is to investigate English language teachers' experience, including their perspectives, along with their awareness with regards to telecollaboration and its related practices within English language classes across various schools in Saudi Arabia. In fact, the first driving force of conducting such a piece of research is to unveil the teachers' competence with telecollaboration, including current understandings of this concept as well as their familiarity towards the implementation of this for the teaching of English as a foreign language (EFL) classes. The second force of carrying out this research is to assess the competence of teachers in terms of telecollaboration before learners get engaged in such practices. This research will also explore the potential challenges confronting teachers; the possible benefits of telecollaboration within the EFL classroom, and to identify the teachers' willingness to work with counter partners from similar or different cultures and to reveal to what extent these teachers are interculturally competent. Accordingly, this research will address the following three research questions:

RQ1) What aspects of telecollaborative competence do correlate with region among EFL teachers in Saudi Arabia, in light of the criteria of telecollaborative teachers?

RQ2) What aspects of telecollaborative competence do correlate with gender among EFL teachers in Saudi Arabia, in light of the criteria of telecollaborative teachers?

RQ3) What aspects of telecollaborative competence do correlate with the qualifications of EFL teachers in Saudi Arabia, in light of the criteria of telecollaborative teachers?

\section{Literature Review}

\subsection{Telecollaboration: Affordances and Challenges}

Telecollaboration is defined as the process of virtual intercultural interaction and collaboration between classes and learners in geographically remote locations under the guidance of educators or facilitators (O'Dowd, 2007). In telecollaborative practices, English as an international language as well as English as the lingua franca (ELF) are commonly used with non-native speakers of English (or possibly with native speaker of English) with a focus on various cultural, local or global issues which promote the practice of language development (Guth \& Helm, 2011). Telecollaboration is also seen as the application of online communication technologies to bring together language learners from dissimilar cultures in various disseminated sites to accelerate language learning skills and to increase their intercultural awareness (O’Dowd, 2013). 
This process of sharing knowledge and exchanging information, with the inclusion of web 2.0 technologies such as Skype, Google.Docs, Podcasts, etc., the aim is to establish communities of learners; regardless of place or time constraints (Coutinho, 2016). The described process is also called virtual exchange, COIL (collaborative online international learning), OIE (online intercultural exchange), e-Tandem, e-Twinning and e-Pals. Based on several studies and projects across the globe, and specifically in Europe (e.g., INTENT, UNICOLLABORATION, TILA), the integration of telecollaboration into classrooms and lecture halls has become valuable for language learners in particular (Cunningham, 2017; Kern, Ware, \& Warschauer, 2017; Alonso-Belmonte \& Vinagre, 2017).

There is evident highlighting sam the benefits of engaging learners' attention to cultural and social uses of the target language (Savignon, 2004). Telecollaboration has been found to promote learner autonomy and experiential learning as learners become responsible for their own learning; along with being considered as a motivating source of learning using synchronous and asynchronous tools (Weller, 2007; O’Dowd \& Waire, 2009). Intercultural encounters help learners to share their views and reflect on each other's cultures in an informal. non-threating environment whereby learners become less anxious in their communications with native speakers, in an attempt to reach proximity and reciprocal support (Furstenberg et al., 2001). Telecollaboration directly encourages learners towards the improvement of interpersonal communication skills (Boston, 2009; Jauregi, 2016). Advanced or native learners can provide their counter-peers with accurate forms and language corrections (Bower \& Kawaguchi, 2011). Anikina, Sobinova and Petrova (2015) agree that telecollaboration is a useful approach for university learners to help them internalize language learning strategies and connect them with other students. Comprehensive telecollaborative interaction takes place when tasks are designed appropriately in light of language skills and intercultural communicative competences (Anikina, Sobinova, \& Petrova, 2015).

On the other hand, and despite the fact that there has been a shift in foreign language teaching and computer-mediated communication (CMC), there are clear challenges, as highlighted through previous research relevant to telecollaboration and telecollaborative practices including institutional constraints, assessment requirements and the continuous need for student support and teacher training (Helm, 2015). Guth, Helm, and O'Dowd (2012) reported the results of a group of practitioners who experienced telecollaborative exchanges. The practitioners were found to benefit from engaging in the telecollaborative process. Nevertheless, they had difficulties with setting up and running exchanges; difficulties with assessments due to institutional requirements; difficulties with lack of pedagogical and technological knowledge and difficulties in finding the appropriate partners.

Research has found out that organizers of telecollaborative projects should take into account how they will be dealing with three levels of potential constraints across the two cohorts or groups of telecollaborators: interaction (individual) level, classroom level and socio-institutional level (O'Dowd \& Ritter, 2006). The first constraint is on an interactional level (individual), which may involve learners' current inter-cultural competencies and their motivation and expectations. The second constraint is at the classroom level, which requires extra effort of thinking in relation to teacher-teacher relationships or inter-communication; task design of appropriate content and logical sequencing; learner matching procedures; local group dynamics and pre-exchange briefing. The last constraint is at the socio-institutional level, which requires appropriate consideration for the use and access of the necessary tools and prestige of the target language and culture. Jauregi (2016) reports that insufficient technological availability, accessibility and network robustness, different pedagogical views and intercultural competence levels of those engaged in telecollaboration partnerships, mismatching communication styles and project expectations and uneven prestige of the target language' are all amongst the challenges which would hinder telecollaborative projects and which teachers of English language must be competent with.

\subsection{Telecollaboration and Task Design}

Creating satisfactory language learning tasks pose as one of the major challenges in telecollaborative-related studies. That is due to the fact that tasks are what give meaning to the learners' explorations which can also ensure the quality of the learning process (Furstenberg, 1997). Tasks are those activities which featured engaging learners in meaningful language use through 'meaningful content, activating learners' resources, choice and clear audience' (Kurek \& Muller-Hartmann, 2017). Designing satisfactory tasks are vital to the incorporation of technological, pedagogical and knowledge content- TPACK (Mishra \& Koehler, 2006). Meskill (1999) provided first thoughts regarding the criteria of designing tasks in computer-assisted language learning (CALL) settings followed by Chapelle's (2001) framework for the evaluation of CALL task appropriateness - that has become popular in telecollaborative research (Wang, 2007).

Nevertheless, due to some conservation on those criteria relevant to CALL task design, further criterion have 
been suggested. Hampel (2006) suggests to include the following principles: learner-centeredness, communicative and collaborative approach and focus on meaning. Furthermore, and due to the need to focus more on the pedagogic task criteria, O'Dowd and Ware (2009) classified telecollaborative tasks into twelve types, including information exchange; comparison and analysis, and collaboration and product creation. Such tasks have been subject to three stages of task sequencing: introduction phase, comparative phase, and intense negotiation phase (O’Dowd \& Ware, 2009). In addition, task design has been influenced by the advancements in computer, media and other technologies. Hauck (2010) confirms that telecollaborative tasks involve 'the development of language proficiency, intercultural communicative competence and new media literacies'.

In the context of telecollaborative online exchanges studies, there is a need to consider a network of core features of task design: such as communication modes, physical locations, pedagogic language constellation and target topics (Hoffstaedter \& Kohn, 2015). Intercultural elements are highly significant, as already noted, and this should be reflected in the designated tasks. O'Dowd and Eberbach (2006) stress the need of raising learners' awareness of the interrelationship between culture and language along with training leaners with regard to how to make culturally linguistic-appropriate posts. Such tasks involve elements of collaboration which requires learners to be more dynamic and involved (Hampel, 2006). Collaborative-oriented tasks 'turns (the) learners' emotive social presence to a cognitive one, pushing participants to engage in higher-level thinking and more intense meaning negotiation' (Kurek, 2015).

\subsection{Telecollaboration and Training Language Teachers}

The training of prospective and current EFL teachers is of paramount importance. Pre-service teachers, in particular, should normally gain experience concerned with telecollaborative exchanges as part of what is known as experiential learning (Hong, 2010). Vinagre (2015) notes the importance of experiential use along with the adaptation of technologies among teachers to prepare them for integrating this skill into the classroom. This experience also promotes teachers to discover and reflect on the mutual interrelationship between technology and pedagogy in authentic, linguistic, intercultural settings (Hubbard \& Levy, 2006). There are further competencies needed to be developed among language teachers including exploratory teaching practice (Hauck \& Wernecke, 2009) and experiential modelling (Fuchs et al., 2012). Such practices reinforce teachers to frequently share thoughts (Harteis, 2010) and socially construct knowledge via active participation, interaction and reflection with the mediation of technologies (Vinagre, 2017). They encourage new pedagogical practices and experiences such as web-oriented collaboration (Dooly, 2009).

Several studies have found that pre-service teachers are lacking adequate exposure to the pedagogical and methodological applications of computer-mediated communication (Brown \& Warschauer, 2006; Lim, Chai, \& Churchil, 2010) and effective problem-based learning tasks (Van Loon, Ros, \& Martens, 2013). Cortina-Perez, et al. (2014) found that sixty percent $(60 \%)$ of teachers had no experience of using web 2.0 interactive tools for academic purposes; despite the fact that the majority of them- nearly ninety percent $(90 \%)$ had received adequate information and communication technologies (ICT)-related training and sixty percent $(60 \%)$ of the teachers had ICT-related certificates and had been on training courses in the past. Telecollaborative teachers need to be fully aware of all pedagogical considerations including making informed choices and decision-making, and best integrating them with tasks and course objectives (Kurek \& Muller-Hartmann, 2017). These competencies are amongst the key competencies of online language teachers which are suggested by Hampel and Stickler (2005) starting from lower level skills (e.g., knowing the constraints of certain software) to advanced level skills (e.g., facilitation of communicative practice).

Many non-trained language teachers do not realize the differences between the two modes of face-to-face and online environments. Hampel (2006) states that moving face-to-face-oriented tasks to online settings, without a transition phase, is a common practice among teachers. Levy, Wang, and Chen (2009) have shown the importance of training language teachers to adopt a reflective approach to advance their telecollaborative professional practices. Del Moral and Villalustre (2010) advocate that telecollaborative professional teachers 'teachers 2.0' often require extended technological expertise in light of three classifications: cognitive competences that refer to the ability of using ICT inside the classroom and basic software package; methodological competences that include knowing how search, process and analyse information online; and organizational competences that involve the ability of integrating various technologies in class in appropriate way.

\subsection{Keys of Telecollaboration Integration Into EFL Classes}

Successful integration of telecollaborative projects is based on comprehensive understanding of what the concept of blended learning involves, along with its relevant ideas and strategies (Levy and Stockwell, 2006). This 
argument has been supported by Garrison and Kanuka (2004) who point out that blended learning tasks play a key role in determining teaching practices and the way online-based tasks can be integrated into various classes and institutions. The integration of tasks ought to be significantly considerable to reach normalization and faculty adoption (Bax, 2003; Keengwee, Kidd, \& Kyei-Blankson, 2009). In order to achieve normalization among educators and faculty adoption, Chambers and Bax (2006) proposed criteria which are related to the institutions and educators involved. The criteria which are related to institutions involves creating the atmosphere of implementing online-based tasks in normal teaching settings; allocating adequate time for teachers to prepare online-based tasks; providing the adequate technological and pedagogical training and making sure that the new design of tasks (online-based) is part of the syllabus.

Other criteria which are dependent on the educators include, based on Chambers and Bax (2006), having digital competence of teachers with feeling confident in using different forms of technologies; the sufficient experience in terms of collaboration and dealing with novice colleagues and learners; and being aware of the challenges and opportunities of technology-related issues. Such criteria are referred to as bottom-up factors those related to teachers themselves while other criteria are defined as top-down factors including the policy-making-related decisions by educational institutions (Keengwee et al., 2009).

In the same vein, an emerging model was developed by Walker and White (2015) who demonstrates a wide range of linguistic capabilities, in addition to digital knowledge and experience, including procedural competence, social-digital competence, digital discourse competence and strategic competence. Such components of digital competence are essential for 'diagnosing, understanding, and repairing the digital needs of learners' (p. 9) which need to be aware of before for successful telecollaborative integration. Procedural competence refers to the ability to manipulate the technology in terms of hardware and software (applications). In short, procedural competence requires a comprehensive understanding of both how and when to use these technologies and the purpose of using them, as well as how to fill the gap between skills and knowledge. Social-digital competence refers to the ability to decide on what knowledge and language are appropriate to use in different social settings. It determines the purpose of communication, what is needed to control privacy, and if certain digital tools fit with and are suitable, according to the norms of a particular context. Digital discourse competence refers to the ability to manage extended tasks using technological tools, including editing, publishing texts, recording texts and then uploading them online, adding photographs and images. Strategic competence includes the ability to deal with problems and also fixing such problems if there are any, which are related to technological knowledge and ICT skills, although not necessarily advanced or sophisticated knowledge (Walker \& White, 2015).

In fact, sustainability for the integration of telecollaborative exchange tasks is a crucial issue to achieve successful global networked-learning environment (Starke-Meyerring \& Wilson, 2008). They advocated that the sustainability of online-oriented tasks demands robust interaction between the efforts that to be made by teachers worldwide and the novel decisions taken various educational institutions. Numerous research studies tackled the impact of blended learning and its supported tasks to telecollaboration (i.e., Dooly, 2008; O'Dowd, 2007); yet, O'Dowd (2010) carried out a major study in this regard to verify types of telecollaborative practices untaken by university educators in Europe. O'Dowd (2013) concluded that several tasks need 'to move from being a peripheral activity employed by isolated pioneers to being widespread practices which are well-known and highly-valued by university educators and management and can be undertaken with relative ease by practitioners when appropriate' (p. 2). Four keys were identified by O'Dowd (2013) to integrate telecollaboration; taking into account that such keys (or factors) are connected to institutions and educators. The keys are:

- $\quad$ to build reliable and steady partnerships;

- to raise awareness and prestige of the telecollaborative exchange in the local institution and beyond;

- to use and blend telecollaboration creatively to adapt to local institutions' needs;

- to achieve credit or recognition for the students' telecollaborative work; and

- to link telecollaboration to broader international activity.

\section{Research Methodology}

In this research, we investigated a group of Saudi EFL teachers in order to explore more insights regarding their telecollaborative competence as well as their experience and willingness to implement telecollaboration within the language learning context. All data - which were given to the participants - were quantitatively and qualitatively analyzed. All the EFL teachers were randomly selected for the questionnaire and interviews across the kingdom of Saudi Arabia. Therefore, the researcher received various responses from numerous EFL teachers 
from different regions of Saudi Arabia, including male and female teachers with diverse ages and teaching experience.

The standardized questionnaire chosen for this research has been adopted from O'Dowd Model of Competent Telecollaborative Teacher. Yet, a few amendments have been made to the existing questionnaire in order to make it more appropriate to the participants of the current study. According to this questionnaire, telecollaborative competence is divided into four main categories: organizational competence, pedagogical competence, digital competence and general attitudes and beliefs about the telecollaborative competent teacher. A chi-square test has been applied to explore the correlation of categorical variables and how they may differ from one another.

The questionnaire was completed by a total of one hundred thirty-eight (138) EFL teachers and consisted of thirty-three (33) statements based on a five likert-scale ranging from to A Great existent to Not at all. The questionnaire was designed electronically using SurveyMonkey software via distributing it randomly to a large community of Saudi EFL teachers. In light of the above-mentioned details, the research has addressed the following three research questions:

RQ1) What aspects of telecollaborative competence do correlate with region among EFL teachers in Saudi Arabia, in light of the criteria of telecollaborative teachers?

RQ2) What aspects of telecollaborative competence do correlate with gender among EFL teachers in Saudi Arabia, in light of the criteria of telecollaborative teachers?

RQ3) What aspects of telecollaborative competence do correlate with the qualifications of EFL teachers in Saudi Arabia, in light of the criteria of telecollaborative teachers?

\section{Results and Data Analysis}

The first research question, which has been addressed in this research, explores correlation across the various regions (i.e., Central, Eastern, Northern, Southern, Western) of the Saudi EFL teachers and some aspects of telecollaborative competence. This involves their experiences and willingness (including their competence) towards the employment of telecollaboration inside EFL classes. This research question has been thought of due to the fact that the location of EFL teachers might have an effect on their familiarity with telecollaboration and its telecollaborative practices. As shown in Table 1, boldface numerals indicate the case of p-values less than 5\%. Based on chi2, this test calculates and displays Pearson's chi-squared for the hypothesis that the rows and columns in a two-way table are independent. If $\mathrm{p}$-value $<0.05$ we reject the null hypothesis of independence.

Based on the results of p-value of Q12 (0.039), Q17 (0.013) and Q20 (0.042), they indicate correlation between region of the EFL teachers and their competence to apply knowledge of the educational context, apply knowledge of the culture and language of the partner class to organize culturally and linguistically rich tasks and to explain to students what is expected from them during an exchange programme. Accordingly, we can reject the null hypothesis of independence between the variables given; demonstrating that such variables (Q12, Q17, and Q20) have an effect on the region of the EFL teachers.

Table 1. Correlation between region \& telecollaborative competence

\begin{tabular}{ll}
\hline Correlation between region \& telecollaborative competence & Pearson Chi 2 \\
\hline Q7. Using online network to locate partner-teachers & 10.3965 \\
& $\operatorname{Pr}=0.581$ \\
$\begin{array}{l}\text { Q8. Establishing and explaining to partner-teachers the expectations related to a possible } \\
\text { exchange }\end{array}$ & 7.9960 \\
Q9. Employing various strategies to 'match' learners from the different institutions & 13.9214 \\
Q10. Maintaining a good working relationship with the partner-teacher & $\operatorname{Pr}=0.306$ \\
& 18.9479 \\
Q11. Articulating virtual partner-teachers the learning objectives and pedagogical beliefs & $\operatorname{Pr}=0.090$ \\
& 4.8805
\end{tabular}


Q12. Applying knowledge of the educational context

\subsection{5}

Pr $=0.039$

Q13. Knowledge of the common causes of organisational and intercultural problems in online exchanges

13.6635

$\operatorname{Pr}=0.323$

Q14. Awareness of measures to ensure that the exchange receives appropriate academic recognition

Q15. Articulate the relevance and the added pedagogical value of telecollaborative exchanges

Q16. Supporting students in reflecting upon culturally contingent patterns of interaction

8.2824

$\operatorname{Pr}=0.763$

7.2340

$\operatorname{Pr}=0.842$

10.8674

$\operatorname{Pr}=0.540$

Q17. Applying knowledge of the culture and language of the partner class to organize culturally and linguistically rich tasks

25.4138

$\operatorname{Pr}=\mathbf{0 . 0 1 3}$

Q18. Designing tasks which are attractive and relevant for students

12.3048

$\operatorname{Pr}=0.422$

Q19. Integrating appropriate assessment procedures

17.9058

$\operatorname{Pr}=0.119$

Q20. Explaining to students what is expected from them during an exchange

21.6166

Pr $=0.042$

Furthermore, the analysis between region and telecollaborative competence has shown a correlation for Q32 with a p-value of (0.003). This result indicates that there is a relationship between the EFL teachers' cities and their competence to accept that the teacher is not the sole authority on the target culture and language. Therefore, we can reject the null hypothesis of independence of specified variables; demonstrating that the difference related to this variable (Q32) has an effect based on the region of the EFL teachers.

Table 2. Correlation between region $\&$ telecollaborative competence

\begin{tabular}{lc}
\hline Correlation between region \& telecollaborative competence & Pearson Chi 2 \\
\hline Q21. Providing learning support for learners either through scaffolded guidance or through & 11.5923 \\
the provision of reflective tools & $\operatorname{Pr}=0.479$ \\
Q22. Choosing the appropriate online communication tools & 10.6638 \\
& $\operatorname{Pr}=0.558$ \\
Q23. Explaining the use of chosen tools to students & 15.4249 \\
& $\operatorname{Pr}=0.219$ \\
Q24. Organizing real-time interaction synchronously and asynchronously & 12.9667 \\
Q25. Interacting appropriately online with partner-teacher & $\operatorname{Pr}=0.371$ \\
Q26. Organizing the online exchange with protecting students' safety and privacy-related & 9.7367 \\
issues & $\operatorname{Pr}=0.639$ \\
Q27. Instructing learners on how to use online tools autonomously & $\operatorname{Pr}=0.964$ \\
Q28. A belief that culture plays an intrinsic role in foreign language education and online & 4.8698 \\
communication & 16.5403 \\
\hline
\end{tabular}


Q29. An openness to partner-teachers' alternative pedagogical beliefs and aims

Q30. An interest in trying out new telecollaborative tasks and new online tools

Q31. A willingness to deal with new messages, texts and questions in contact classes or tutorials

Q32. A willingness to accept that the teacher is not the sole authority on the target culture and language

Q33. Interest in learning with students about new aspects of L2 language use and cultural products and practices
5.3614

$\operatorname{Pr}=0.945$

6.2331

$\operatorname{Pr}=0.904$

11.1469

$\operatorname{Pr}=0.516$

29.8537

$\operatorname{Pr}=\mathbf{0 . 0 0 3}$

17.7532

$\operatorname{Pr}=0.123$

To be able to classify the 'telecollaborative competence' aspects in relation to region, we assign scores $1,2,3$ and 4 to these four levels. We use the ordinal variables: Not at all $=1$, Very little $=2$, Somewhat $=3$ and To a great extent $=4$. Chart 1 compares the mean of aspects of telecollaborative competence across regions (Mean of Q7-Q33). As indicated earlier, the analysis has shown no differences between regions.

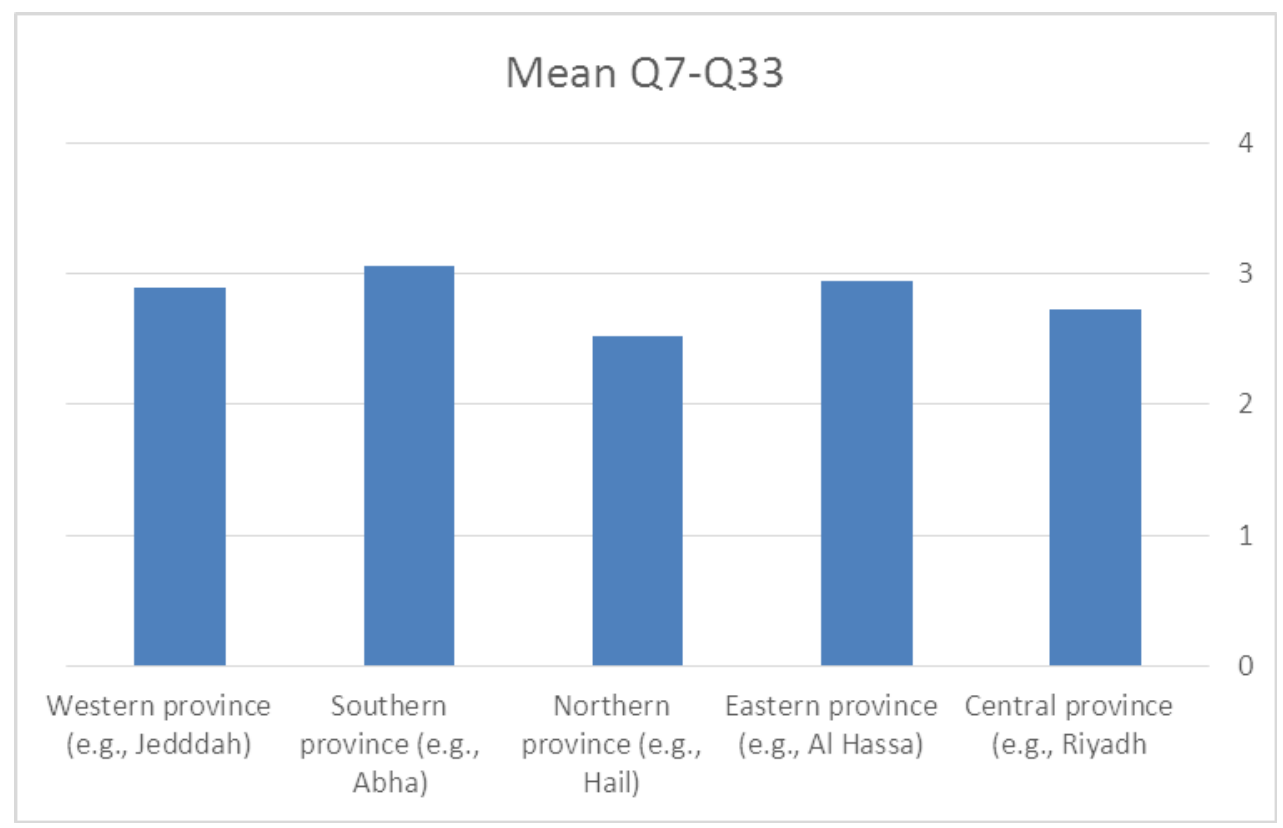

Chart 1. Total responses of EFL teachers by region

The second research question attempts to investigate the correlation between gender (male/female) of the Saudi EFL teachers and some aspects of telecollaborative competence. As shown in Table 3, bold indicates the case of p-values less than 5\%. Based on chi2, this test calculates and displays Pearson's chi-squared for the hypothesis that the rows and columns in a two-way table are independent. If p-value $<0.05$ we reject the null hypothesis of independence.

The findings have shown that p-value of the following questions: Q13 (0.004), Q14 (0.045), Q15 (0.053), Q16 (0.003), Q17 (0.001) and Q19 (0.035) have shown correlation between the gender of the EFL teachers and their telecollaborative competence in relation to knowledge of the common causes of organisational and intercultural problems in online exchanges; awareness of measures to ensure that the exchange receives appropriate academic recognition; articulating the relevance and the added pedagogical value of telecollaborative exchanges; supporting students in reflecting upon culturally contingent patterns of interaction; applying knowledge of the culture and language of the partner class to organize culturally and linguistically rich tasks and integrating appropriate assessment procedures. 
Accordingly, we can reject the null hypothesis of independence between the variables given; which confirm that such variables (Q13- Q17 and Q19) have an effect based on the gender of EFL teachers.

Table 3. Correlation between gender \& telecollaborative competence

\begin{tabular}{|c|c|c|c|}
\hline \multirow[t]{2}{*}{ Correlation between gender \& telecollaborative competence } & \multicolumn{3}{|l|}{ Gender } \\
\hline & $\begin{array}{l}\text { Male } \\
\text { (N0/100\%) }\end{array}$ & $\begin{array}{l}\text { Female } \\
(\mathrm{N} 0 / \mathbf{1 0 0} \%)\end{array}$ & Pearson Chi 2 \\
\hline \multirow[t]{2}{*}{ Q7. Using online network to locate partner-teachers } & 73 & 63 & 1.1898 \\
\hline & $53.68 \%$ & 46.32 & $\operatorname{Pr}=0.755$ \\
\hline \multirow{2}{*}{$\begin{array}{l}\text { Q8. Establishing and explaining to partner-teachers the } \\
\text { expectations related to a possible exchange }\end{array}$} & 73 & 62 & 2.9541 \\
\hline & 54.07 & 54.93 & $\operatorname{Pr}=0.399$ \\
\hline \multirow{2}{*}{$\begin{array}{l}\text { Q9. Employing various strategies to 'match' learners from the } \\
\text { different institutions }\end{array}$} & 73 & 62 & 5.7334 \\
\hline & 54.07 & 54.93 & $\operatorname{Pr}=0.125$ \\
\hline \multirow{2}{*}{$\begin{array}{l}\text { Q10. Maintaining a good working relationship with the } \\
\text { partner-teacher }\end{array}$} & 73 & 62 & 1.2059 \\
\hline & 54.07 & 45.93 & $\operatorname{Pr}=0.752$ \\
\hline \multirow{2}{*}{$\begin{array}{l}\text { Q11. Articulating virtual partner-teachers the learning } \\
\text { objectives and pedagogical beliefs }\end{array}$} & 73 & 61 & 7.6806 \\
\hline & 54.48 & 45.52 & $\operatorname{Pr}=0.053$ \\
\hline \multirow[t]{2}{*}{ Q12. Applying knowledge of the educational context } & 73 & 61 & 6.4099 \\
\hline & 54.48 & 45.52 & $\operatorname{Pr}=0.093$ \\
\hline \multirow{2}{*}{$\begin{array}{l}\text { Q13. Knowledge of the common causes of organisational and } \\
\text { intercultural problems in online exchanges }\end{array}$} & 73 & 62 & 13.2712 \\
\hline & 54.07 & 45.39 & $\operatorname{Pr}=0.004$ \\
\hline \multirow{2}{*}{$\begin{array}{l}\text { Q14. Awareness of measures to ensure that the exchange } \\
\text { receives appropriate academic recognition }\end{array}$} & 73 & 62 & 8.0516 \\
\hline & 54.07 & 45.39 & $\operatorname{Pr}=0.045$ \\
\hline \multirow{2}{*}{$\begin{array}{l}\text { Q15. Articulate the relevance and the added pedagogical value } \\
\text { of telecollaborative exchanges }\end{array}$} & 73 & 61 & 7.6985 \\
\hline & 54.48 & 45.52 & $\operatorname{Pr}=0.053$ \\
\hline \multirow{2}{*}{$\begin{array}{l}\text { Q16. Supporting students in reflecting upon culturally } \\
\text { contingent patterns of interaction }\end{array}$} & 73 & 61 & 14.1530 \\
\hline & 54.48 & 45.52 & $\operatorname{Pr}=0.003$ \\
\hline \multirow{2}{*}{$\begin{array}{l}\text { Q17. Applying knowledge of the culture and language of the } \\
\text { partner class to organize culturally and linguistically rich tasks }\end{array}$} & 73 & 61 & 16.9567 \\
\hline & 54.48 & 45.52 & $\operatorname{Pr}=0.001$ \\
\hline \multirow{2}{*}{$\begin{array}{l}\text { Q18. Designing tasks which are attractive and relevant for } \\
\text { students }\end{array}$} & 73 & 61 & 3.3361 \\
\hline & 54.48 & 45.52 & $\operatorname{Pr}=0.343$ \\
\hline \multirow[t]{2}{*}{ Q19. Integrating appropriate assessment procedures } & 73 & 62 & 8.6149 \\
\hline & 54.07 & 45.39 & $\operatorname{Pr}=0.035$ \\
\hline \multirow{2}{*}{$\begin{array}{l}\text { Q20. Explaining to students what is expected from them during } \\
\text { an exchange }\end{array}$} & 73 & 61 & 4.2970 \\
\hline & 54.48 & 45.52 & $\operatorname{Pr}=0.231$ \\
\hline
\end{tabular}

In addition, the analysis of correlation between gender and a group of aspects of telecollaborative competence, as shown in Table 4, have revealed that most of such aspects have correlation. A statistical correlation was found for the following: Q21 (p-value= 0.033), Q22 ( $\mathrm{p}$-value= 0.042), Q23 (p-value=0.007), Q24 (p-value= 0.004), Q25 $(\mathrm{p}-\mathrm{value}=0.046), \mathrm{Q} 26(\mathrm{p}-\mathrm{value}=0.010), \mathrm{Q} 27(\mathrm{p}-\mathrm{value}=0.023), \mathrm{Q} 29(\mathrm{p}-\mathrm{value}=0.019), \mathrm{Q} 30(\mathrm{p}-\mathrm{value}=0.056)$, Q32 (p-value $=0.026$ ). For example, these results suggest that there is a relationship between EFL teachers' gender and their competence to choose the appropriate online tools; organize real-time and non-real-time interaction and instruct learners how to use online tools autonomously.

For that reason, we can reject the null hypothesis of independence of the specified variables which ensure that 
the differences related to these variables (Q21-Q29, Q30 and Q32) are affected by the gender of the EFL teachers.

Table 4. Correlation between gender \& telecollaborative competence

\begin{tabular}{|c|c|c|c|}
\hline \multirow[t]{2}{*}{ Correlation between gender \& telecollaborative competence } & \multicolumn{3}{|l|}{ Gender } \\
\hline & $\begin{array}{l}\text { Male } \\
(\mathrm{N} 0 / 100 \%)\end{array}$ & $\begin{array}{l}\text { Female } \\
(\mathrm{N} 0 / 100 \%)\end{array}$ & $\begin{array}{l}\text { Pearson } \\
\text { Chi } 2\end{array}$ \\
\hline \multirow{2}{*}{$\begin{array}{l}\text { Q21. Providing learning support for learners either through scaffolded } \\
\text { guidance or through the provision of reflective tools }\end{array}$} & 73 & 62 & 8.7265 \\
\hline & 54.93 & 45.93 & $\operatorname{Pr}=\mathbf{0 . 0 3 3}$ \\
\hline \multirow[t]{2}{*}{ Q22. Choosing the appropriate online communication tools } & 72 & 61 & 8.1825 \\
\hline & 54.14 & 45.86 & $\operatorname{Pr}=0.042$ \\
\hline \multirow[t]{2}{*}{ Q23. Explaining the use of chosen tools to students } & 72 & 62 & 12.0245 \\
\hline & 53.73 & 46.27 & $\operatorname{Pr}=0.007$ \\
\hline \multirow{2}{*}{$\begin{array}{l}\text { Q24. Organizing real-time interaction synchronously and } \\
\text { asynchronously }\end{array}$} & 73 & 62 & 13.1621 \\
\hline & 54.07 & 45.93 & $\operatorname{Pr}=0.004$ \\
\hline \multirow[t]{2}{*}{ Q25. Interacting appropriately online with partner-teacher } & 73 & 62 & 7.9817 \\
\hline & 54.07 & 45.93 & $\operatorname{Pr}=0.046$ \\
\hline \multirow{2}{*}{$\begin{array}{l}\text { Q26. Organizing the online exchange with protecting students' safety } \\
\text { and privacy-related issues }\end{array}$} & 72 & 62 & 11.4442 \\
\hline & 53.73 & 46.27 & $\operatorname{Pr}=0.010$ \\
\hline \multirow[t]{2}{*}{ Q27. Instructing learners on how to use online tools autonomously } & 72 & 62 & 9.5451 \\
\hline & 54.07 & 45.93 & $\operatorname{Pr}=0.023$ \\
\hline \multirow{2}{*}{$\begin{array}{l}\text { Q28. A belief that culture plays an intrinsic role in foreign language } \\
\text { education and online communication }\end{array}$} & 72 & 62 & 3.9223 \\
\hline & 54.07 & 45.93 & $\operatorname{Pr}=0.270$ \\
\hline \multirow{2}{*}{$\begin{array}{l}\text { Q29. An openness to partner-teachers' alternative pedagogical beliefs } \\
\text { and aims }\end{array}$} & 72 & 62 & 9.9360 \\
\hline & 54.07 & 45.93 & $\operatorname{Pr}=0.019$ \\
\hline \multirow{2}{*}{$\begin{array}{l}\text { Q30. An interest in trying out new telecollaborative tasks and new } \\
\text { online tools }\end{array}$} & 72 & 62 & 7.5475 \\
\hline & 54.07 & 45.93 & $\operatorname{Pr}=0.056$ \\
\hline \multirow{2}{*}{$\begin{array}{l}\text { Q31. A willingness to deal with new messages, texts and questions in } \\
\text { contact classes or tutorials }\end{array}$} & 73 & 62 & 5.8459 \\
\hline & 54.07 & 45.93 & $\operatorname{Pr}=0.119$ \\
\hline \multirow{2}{*}{$\begin{array}{l}\text { Q32. A willingness to accept that the teacher is not the sole authority } \\
\text { on the target culture and language }\end{array}$} & 73 & 62 & 9.2601 \\
\hline & 54.07 & 45.93 & $\operatorname{Pr}=0.026$ \\
\hline \multirow{2}{*}{$\begin{array}{l}\text { Q33. Interest in learning with students about new aspects of L2 } \\
\text { language use and cultural products and practices }\end{array}$} & 73 & 62 & 2.0440 \\
\hline & 54.07 & 45.93 & $\operatorname{Pr}=0.563$ \\
\hline
\end{tabular}

To be able to classify 'telecollaborative competence' aspects in relation to gender, we assign scores 1, 2, 3 and 4 to these four levels. We use the ordinal variables: Not at all $=1$, Very little $=2$, Somewhat $=3$ and To a great extent $=4$. Chart 2 compares the mean of aspects of telecollaborative competence and gender (Mean of Q7-Q33). Little differences between males and females have been found. At a global level the mean for males is 3 (Somewhat) and for females is 2 (very little). 


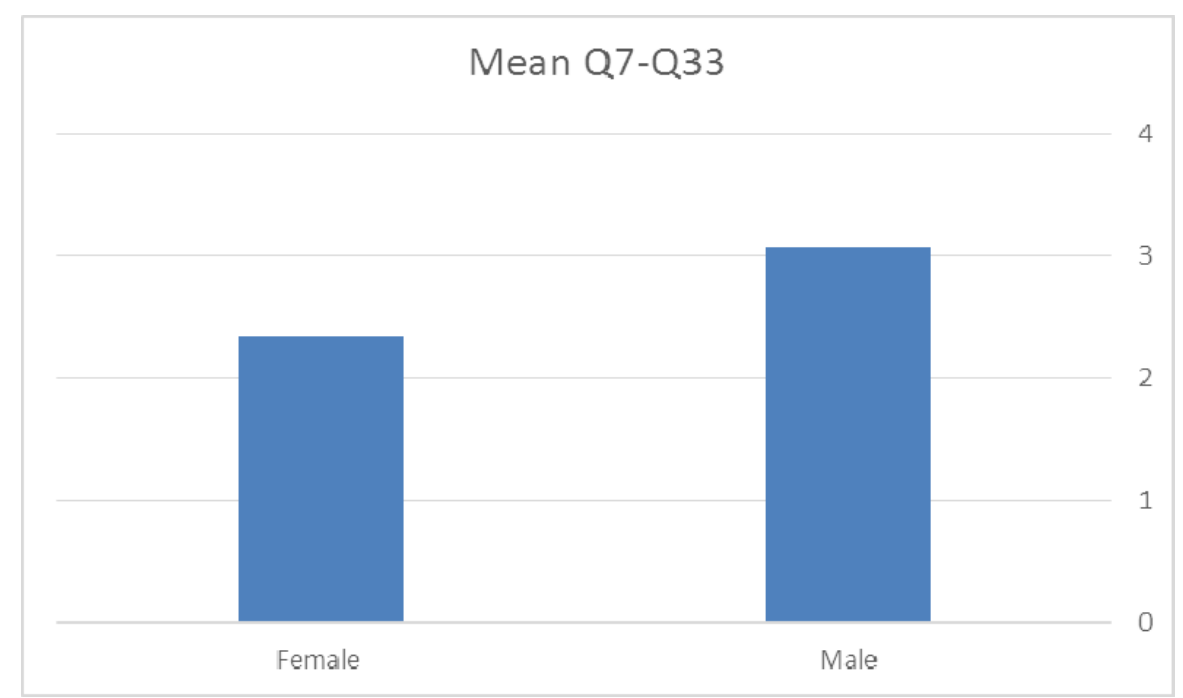

Chart 2. Total responses of EFL teachers by gender

As far as the third research question is concerned, the findings have shown correlation across qualifications (i.e., diploma, bachelor and master) of the Saudi EFL teachers and some aspects of telecollaborative competence. The questions which have been emphasized in boldface indicate the case of p-value less than $5 \%$. On the basis of using chi2, the findings have shown correlation across various qualifications of the EFL teachers and most of the aspects of telecollaborative competence as shown below in Table 5 .

Consequently, the statistical analysis has shown the following results: Q7 ( $\mathrm{p}$-value $=0.002), \mathrm{Q} 8$ (p-value $=0.000$ ), $\mathrm{Q} 9$ ( $\mathrm{p}$-value= 0.019), Q12 (p-value= 0.002), Q14 (p-value=0.001), Q16 (p-value=0.002). For example, these results advocate that there is a relationship between the EFL teachers' qualifications and their competence in what is related to using online network to locate partner-teachers; employing various strategies to 'match' learners from the different institutions and creating awareness of measures to ensure that the exchange receives appropriate academic recognition and encouraging students' reflection upon culturally contingent patterns of interaction.

For that reason, we can reject the null hypothesis of independence of the specified variables which asserts that these variables (Q7-Q12, Q14, and Q16) have effects on the qualification of EFL teachers.

Table 5.Correlation between qualification \& telecollaborative competence

\section{Correlation between qualification $\&$ telecollaborative competence}

Q7. Using online network to locate partner-teachers

Q8. Establishing and explaining to partner-teachers the expectations related to a possible exchange

Q9. Employing various strategies to 'match' learners from the different institutions

Q10. Maintaining a good working relationship with the partner-teacher

Q11. Articulating virtual partner-teachers the learning objectives and pedagogical beliefs

\section{Pearson Chi 2}

20.4337

$\operatorname{Pr}=0.002$

27.1068

$\operatorname{Pr}=0.000$

15.1151

$\operatorname{Pr}=0.019$

11.1037

$\operatorname{Pr}=0.085$

11.1452

$\operatorname{Pr}=0.084$ 
Q12. Applying knowledge of the educational context

21.0497

$\operatorname{Pr}=0.002$

Q13. Knowledge of the common causes of organisational and intercultural problems in online exchanges

8.7696

$\operatorname{Pr}=0.187$

Q14. Awareness of measures to ensure that the exchange receives appropriate academic recognition

23.5125

$\operatorname{Pr}=0.001$

Q15. Articulate the relevance and the added pedagogical value of telecollaborative exchanges

11.5810

$\operatorname{Pr}=0.072$

Q16. Supporting students in reflecting upon culturally contingent patterns of interaction

$\mathbf{2 0 . 8 3 8 7}$

$\operatorname{Pr}=0.002$

Q17. Applying knowledge of the culture and language of the partner class to organize culturally and linguistically rich tasks

12.6202

$\operatorname{Pr}=0.049$

Q18. Designing tasks which are attractive and relevant for students

5.9964

$\operatorname{Pr}=0.424$

Q19. Integrating appropriate assessment procedures

4.1123

$\operatorname{Pr}=0.661$

7.3548

$\operatorname{Pr}=0.289$

Finally, two more questions (Q25 and Q29 with p=values 0.042 and 0.08 respectively) resulted from the analysis of the correlation between qualification and a group of aspects of telecollaborative competence (Table 6). For further details, the outcomes of the analysis have sought out the correlation between EFL teachers' qualification and their competence concerning interacting appropriately online with partner-teacher and establishing an openness to partner-teachers' alternative pedagogical beliefs and aims.

In view of that, we can reject the null hypothesis of independence of the specified variables which confirm that the differences of these two variables (Q25 and Q29) have effects on the qualifications of EFL teachers.

Table 6. Correlation between qualification $\&$ telecollaborative competence

\begin{tabular}{ll}
\hline Correlation between qualification \& telecollaborative competence & Pearson Chi 2 \\
\hline $\begin{array}{l}\text { Q21. Providing learning support for learners either through scaffolded guidance or through the } \\
\text { provision of reflective tools }\end{array}$ & 8.9127 \\
Q22. Choosing the appropriate online communication tools & $\operatorname{Pr}=0.179$ \\
& 6.4024 \\
Q23. Explaining the use of chosen tools to students & $\operatorname{Pr}=0.380$ \\
& 7.0894 \\
Q24. Organizing real-time interaction synchronously and asynchronously & $\operatorname{Pr}=0.313$ \\
& 11.8313 \\
Q25. Interacting appropriately online with partner-teacher & $\operatorname{Pr}=0.066$ \\
& $\mathbf{1 3 . 0 3 7 8}$ \\
Q26. Organizing the online exchange with protecting students' safety and privacy-related & $\mathbf{P r}=\mathbf{0 . 0 4 2}$ \\
issues & 3.9297 \\
Q27. Instructing learners on how to use online tools autonomously & $\operatorname{Pr}=0.686$ \\
& 2.4018 \\
\hline
\end{tabular}


Q28. A belief that culture plays an intrinsic role in foreign language education and online communication

Q29. An openness to partner-teachers' alternative pedagogical beliefs and aims

Q30. An interest in trying out new telecollaborative tasks and new online tools

Q31. A willingness to deal with new messages, texts and questions in contact classes or tutorials

Q32. A willingness to accept that the teacher is not the sole authority on the target culture and language

Q33. Interest in learning with students about new aspects of L2 language use and cultural products and practices

\subsection{2}

$\operatorname{Pr}=0.147$

17.4502

Pr $=0.008$

3.0259

$\operatorname{Pr}=0.806$

2.9426

$\operatorname{Pr}=0.816$

3.2513

$\operatorname{Pr}=0.777$

4.3473

$\operatorname{Pr}=0.630$

\section{Discussion}

Several studies have investigated the potential of integrating telecollaboration into classes in EFL settings, such as Cunningham, 2017; Kern, Ware, and Warschauer, 2017; Alonso-Belmonte and Vinagre, 2017. Nevertheless, there is still limited research which has looked at the connection, along with effectiveness, between telecollaborative competences of EFL teachers and their background: region, gender, and qualifications and what influences they may have. This research has shown that these three factors may have an impact on some elements of the telecollaborative competences required by EFL teachers.

As reflective practice and dealing with intercultural challenges have been found correlating with gender and qualification among telecollaborative EFL teachers, Hubbard and Levy (2006) argue that technology, pedagogy and the nature of distribution of tasks are always inseparable. The analysis revealed the significance of social-oriented construction of knowledge, which is based on participation, interaction, and reflection (Vinagre, 2017).

Indeed, data analysis has confirmed the influence of interacting with partner-teachers from different institutions and choosing suitable communication tools on telecollaboration. That is to provide them with immediate language correction and corrective feedback (Bower \& Kawaguch, 2011). O'Dowd (2013) claims that these two features are crucial in telecollaboration as to boost language learning skills and comprehend others' cultures.

Assessing telecollaborative competences among current EFL teachers resulted in highlighting elements of telecollaboration which need addressing, such as training teachers to not regard themselves as the sole authority. This has been supported by Hauck and Wernecke (2009) and Fuchs et al. (2012) that such types of teachers must be exposed to further competences such as exploratory teaching practice, authentic learning, and experiential modelling. The contribution of such analysis would contribute to verifying the correlational effect of region, gender and qualification telecollaborative competence of EFL teachers. The results will also be a step forward towards understanding this approach in order to appropriately implement shared language learning strategies as suggested by Anikina, Sobinova, and Petrova (2015).

\section{Conclusion and Suggestions for Future Research}

On the basis of the results given, telecollaboration can be effective when there is a consistent partnership between institutions and participants, an adequate level of awareness and achievement of appreciation of users, and a connection of telecollaboration to other activities and tasks taking place at institutions (O'Dowd, 2013). It has been realized that telecollaboration is a gradual process when it becomes something that is appreciated and apparent to students, faculty and institution management. It will also heavily depend on time and effort given to the change in syllabi and development of relationships with various telecollaborative partners in similar and different institutions.

Future research is suggested to take into account the qualitative aspects of assessing EFL teachers in Saudi Arabia including their experience and competence towards using telecollaboration. Such research may concentrate on interviewing a group of EFL teachers or conducting focus group analysis of a large group of Saudi EFL teachers. The following question can be placed as a key research question: what are teachers' 
experiences, willingness and their pre-judgment with regard to integrating telecollaboration into EFL classes?

In addition, the following questions can be promoted for individual interviews as well as group discussions:

Have you heard the term telecollaboration or language exchange programs before? Explain.

What do you think about integrating cultural elements into teaching L2?

Do you have any experience of engaging with a native English language teacher through social networking technologies such as Skype or video-conferencing in class?

Do you see that intercultural understanding among EFL teachers exists or not? Why?

Do you think that telecollaborative practice is possible in your context where language exchange practice can be used? Why?

Through answering such questions by the participants it would be possible to identify barriers and values of telecollaboration, current practices of EFL teachers and future implementation, nature of tasks and appropriate tools or technologies which are appropriate.

\section{References}

Alonso-Belmonte, I., \& Vinagre, M. (2017). Interculturality and identity in computer-mediated communication: findings from L2 teaching contexts. Computer-assisted Language Learning, 30(5), 343-350. https://doi.org/10.1080/09588221.2017.1321329

Anikina, Z., Sobinova, L., \& Petrova, G. (2015). Integrating telecollaboration into EFL classroom: Theoretical and practical implications. Procedia-Social and Behavioral Sciences, 206, 156-161. https://doi.org/10.1016/j.sbspro.2015.10.045

Bax, S. (2003). CALL - Past, present and future. System, 31(1), 13-28. https://doi.org/10.1016/S0346-251X(02)00071-4

Bower, J., \& Kawaguchi, S. (2011). Negotiation of meaning and corrective feedback in Japanese/English eTandem. Language Learning and Technology, 15(1), 41-71.

Brown, D., \& Warschauer, M. (2006). From the university to the elementary classroom: Students' experiences in learning to integrate technology in instruction. Journal of Technology and Teacher Education, 14(3), 599.

Chambers, A., \& Bax, S. (2006). Making CALL work: Towards Normalisation. System, 34(4), 465-479. https://doi.org/10.1016/j.system.2006.08.001

Chapelle, C. A. (2001). Computer applications in second language acquisition: Foundations for teaching, testing and research. Cambridge: Cambridge University Press. https://doi.org/10.1017/CBO9781139524681

Cunningham, D. J. (2017). Methodological Innovation for the Study of Request Production in Telecollaboration. Language Learning and Technology, 21(1), 76-99.

Coutinho, M. (2016). Using a Telecollaboration Exchange Web 2.0 in a Second Language Classroom. US-China Education Review, 6(10), 603-609.

Del Moral, M. E., \& Villalustre, L. (2010). Formacion del profesor 2.0: Desarrollo de competencias tecnologicas para la escuela 2.0. Revista Miscelánea de Investigación, 23, 59-70.

Dooly, M. (2009). New competencies in a new era? Examining the impact of a teacher training project. ReCALL, 21(3), 352e369. https://doi.org/10.1017/S0958344009990085

Dooly, M. (2008). Constructing Knowledge Together. In P. Lang (Ed.) Telecollaborative Language Learning: A guidebook to moderating intercultural collaboration online (pp. 21-45). Bern.

Fuchs, C., Hauck, M., \& Müller-Hartmann, A. (2012). Promoting learner autonomy through multiliteracy skills development in cross-institutional exchanges. Language Learning and Technology, 16(3), 82-102.

Furstenberg, G. (1997). Teaching with technology: What is at stake? ADFL Bulletin, 28(3), 21-25. https://doi.org/10.1632/adfl.28.3.21

Furstenberg, G., Levet, S., English, K., \& Maillet, K. (2001). Giving a virtual voice to the silent language of culture: The culture project. Language, Learning and Technology, 5(1), 55-102.

Garrison, D., \& Kanuka, H. (2004). Blended learning: Uncovering its transformative potential in higher education. The Internet and Higher Education, 7(2), 95-105. https://doi.org/10.1016/j.iheduc.2004.02.001

Guth, S., \& Helm, F. (2011). Developing multiliteracies in ELT through telecollaboration. ELT Journal, 66(1), 
42-51. https://doi.org/10.1093/elt/ccr027

Guth, S., Helm, F., \& O’Dowd, R. (2012). University language classes collaborating online. A Report on the Integration of Telecollaborative Networks in European Universities. Retrieved from https://www.unicollaboration.org/wp-content/uploads/2016/06/1.1-Telecollaboration_report_Executive_su mmary-Oct2012_0.pdf

Hubbard, P., \& Levy, M. (2006b). The scope of CALL education. In P. Hubbard, \& M. Levy, (Eds.), Teacher education in CALL (pp. 3-20). Philadelphia: Benjamins. https://doi.org/10.1075/1llt.14.04hub

Hampel, R. (2006) Rethinking task design for the digital age: A framework for language teaching and learning in a synchronous online environment. ReCALL, 18(1), 105-121. https://doi.org/10.1017/S0958344006000711

Hampel, R., \& Stickler, U. (2005). New skills for new classrooms. Training tutors to teach languages online. Computer Assisted Language Learning, 18(4), 311-326. https://doi.org/10.1080/09588220500335455

Harteis, C. (2010). Contributions of e-collaborative knowledge construction to professional learning and expertise. In B. Erlt (Ed.), E-Collaborative knowledge Construction: Learning from computer-supported and virtual Environments (pp. 91-108). Hershey: IGI Global. https://doi.org/10.4018/978-1-61520-729-9.ch005

Hauck, M. (2010). Telecollaboration: At the Interface between Multimodal and Intercultural Communicative. In S. Guth, \& F. Helm (Eds.), Telecollaboration 2.0: Language, Literacies and Intercultural Learning in the 21st Century (1, 219), New York: Peter Lang.

Hauck, M., \& Wernecke, S. (2013). Designing CALL materials for social presence. In M. Thomas, H. Reinders, \& M. Warschauer (Eds.), Contemporary Computer-assisted Language Learning (pp. 95-115), London and New York: Continuum.

Helm, F. (2015). The Practices and Challenges of Telecollaboration in Higher Education in Europe. Language Learning and Technology, 19(2), 197-217.

Hoffstaedter, K., \& Kohn, K. (2015). Telecollaboration for intercultural foreign language conversations in secondary school contexts: Task design and pedagogic implementation. TILA Research Results on Telecollaboration.

Hong, K. H. (2010). CALL teacher education as an impetus for L2 teachers in integrating technology. ReCALL, 22(1), 53-69. https://doi.org/10.1017/S095834400999019X

Keengwee, J., Kidd, T., \& Kyei-Blankson, L. (2009). Faculty and technology: Implications for faculty training and technology leadership. Journal of Science Education and Technology, 18(1), 23-28. https://doi.org/10.1007/s10956-008-9126-2

Kern, R., Ware, P., \& Warschauer, M. (2017). Network-based language teaching. Second and Foreign Language Education, Encyclopaedia of Language and Education, Springer (pp. 197-209).

Kurek, M. (2015). Designing tasks for complex virtual learning environments. Bellaterra Journal of Teaching and Learning Language and Literature, 8(2), 13-32. https://doi.org/10.5565/rev/jtl3.633

Kurek, M., \& Müller-Hartmann, A. (2017). Task design for telecollaborative exchanges: In search of new criteria. System, 64, 7-20. https://doi.org/10.1016/j.system.2016.12.004

Levy, M., \& Stockwell, G. (2006). CALL dimensions: Options and issues in computer assisted language learning. New Jersey: Lawrence Erlbaum and Associates.

Levy, M., Wang, Y., \& Chen, N.-S. (2009). Developing the skills and techniques for online language teaching: A focus on the process. Innovation in Language Learning and Teaching, 3(1), 17-34. https://doi.org/10.1080/17501220802655417

Lim, C. P., Chai, C. S., \& Churchill, D. (2011). A framework for developing pre - service teachers' competencies in using technologies to enhance teaching and learning. Educational Media International, 48(2), 69-83. https://doi.org/10.1080/09523987.2011.576512

Mishra, P., \& Koehler, M. J. (2006). Technological pedagogical content knowledge: A framework for teacher knowledge. Teachers College Record, 108(6), 1017. https://doi.org/10.1111/j.1467-9620.2006.00684.x

Meskill, C. (1999). Computers as tools for sociocollaborative language learning. In K. Cameron (Ed.), Computer assisted language learning (CALL): Media, design and applications (pp. 141-162). Lisse: Swets and Zeitlinger. 
O’Dowd, R. (Ed.). (2007). Online intercultural exchange: an introduction for foreign language teachers. Clevedon, UK: Multilingual Matters.

O'Dowd, R. (2010). Online foreign language interaction: Moving from the periphery to the core of foreign language education. Language Teaching, 44(3), 368-380. https://doi.org/10.1017/S0261444810000194

O'Dowd, R. (2013). The competences of the telecollaborative teacher. The Language Learning Journal, 1-14.

O'Dowd, R., \& Ritter, M. (2006). Understanding and working with'failed communication'in telecollaborative exchanges. CALICO Journal, 623-642.

O'Dowd, R., \& Ware, P. (2009). Critical issues in telecollaborative task design. Computer Assisted Language Learning, 22(2), 173-188. https://doi.org/10.1080/09588220902778369

O'Dowd, R., \& Eberbach, K. (2004). Guides on the Side? Tasks and Challenges for Teachers in Telecollaborative Projects. ReCALL, 16(1), 129-144. https://doi.org/10.1017/S0958344004000217

Savignon, S. J., \& Roithmeier, W. (2004). Computer-mediated communication: Texts and strategies. CALICO Journal, 21(2). 265-290. https://doi.org/10.1558/cj.v21i2.265-290

Starke-Meyerring, D., \& Wilson, M. (2008). Learning environments for a globally networked world: Emerging visions. In D. Starke-Meyerring \& M. Wilson (Eds.), Designing globally networked learning environments: Visionary partnerships, policies, and pedagogies (pp. 1-17). Sense Publishers.

Van Loon, A.-M., Ros, A., \& Martens, R. (2013). Designing digital problem based learning tasks that motivate students. Journal of Technology and Education, 21(4), 409-432.

Vinagre, M. (2016). Training teachers for virtual collaboration: A case study. British Journal of Educational Technology, 47(4), 787-802. https://doi.org/10.1111/bjet.12363

Vinagre, M. (2017). Developing teachers' telecollaborative competences in online experiential learning. System, 64, 34-45. https://doi.org/10.1016/j.system.2016.12.002

Walker, A., \& White, G. (2013). Technology Enhanced Language Learning: connecting theory and practice-Oxford Handbooks for Language Teachers. Oxford University Press.

Wang, Y. (2007). Task design in videoconferencing supported distance language learning. CALICO Journal, 24(3), 591-630. https://doi.org/10.1558/cj.v24i3.591-630

Weller, M. (2007). Virtual Learning Environments. London: Routledge.

\section{Appendices}

Appendix 1. Demographic information

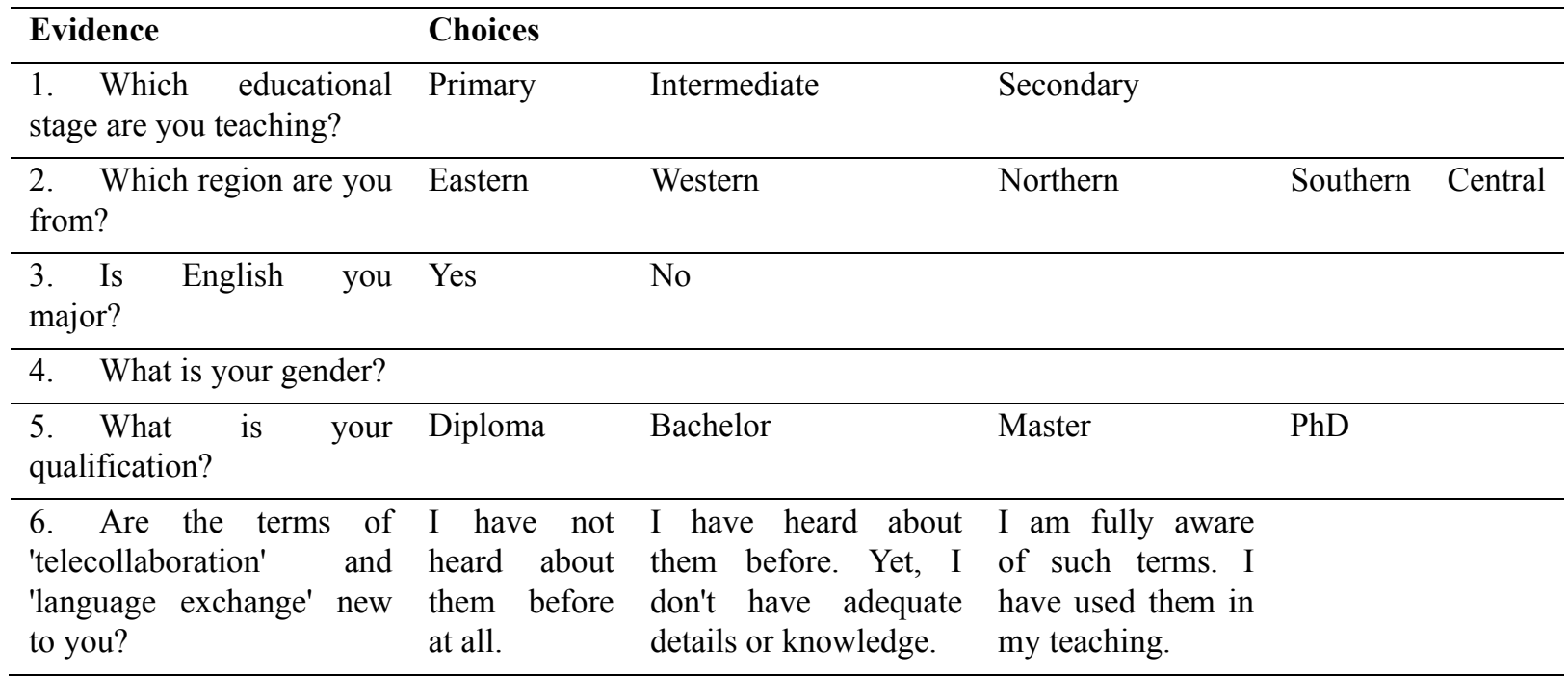


Appendix 2. Questionnaires (adapted from O'Dowd, 2013 - model of telecollaborative teacher)

\begin{tabular}{llllll}
\hline Evidence & $\begin{array}{l}\text { To a great } \\
\text { extent }\end{array}$ & Somewhat & $\begin{array}{l}\text { Very } \\
\text { little }\end{array}$ & $\begin{array}{l}\text { Not at } \\
\text { all }\end{array}$ \\
\hline & 1 & 2 & 3 & 4 \\
\hline
\end{tabular}

Organizational competence of the telecollaborative teacher: I can ...

7. use online network to locate partner-teachers in distant location.

8. establish and explain clearly to possible partner-teachers the expectations related to a possible exchange.

9. employ various strategies to 'match' learners from the different institutions and to create effective partnerships and exchange groups.

10. maintain a good working relationship with the partner-teacher throughout the exchange, identifying problems as they arise.

11. articulate virtual partner-teachers the learning objectives and pedagogical beliefs that lie behind his/her proposed tasks.

12. apply knowledge of the educational context in which the partner class is working in order to structure the exchange and avoid problems.

13. have knowledge of the common causes of organisational and intercultural problems in online exchanges and can apply a series of techniques and strategies to deal with these problems.

14. have awareness of measures to ensure that the exchange receives appropriate academic recognition within the home institution

15. can successfully articulate the relevance and the added pedagogical value of telecollaborative exchanges to colleagues and superiors in order to support their use throughout the institution.

\section{Pedagogical competence of the telecollaborative teacher: I can ...}

16. support students in reflecting upon culturally contingent patterns of interaction in follow-up classroom discussions.

17. apply knowledge of the culture and language of the partner class to organize culturally and linguistically rich tasks for the exchange.

18. design tasks which are attractive and relevant for students and which serve to develop culturally and linguistically rich interaction.

19. integrate appropriate assessment procedures which accurately reflect the activities which students carried out during their exchange.

20. explain clearly to students what is expected from them during an exchange - deadlines, performance objectives, learning outcomes etc. 
21. provide learning support for learners either through scaffolded guidance (in the classroom or in online tutorials) or through the provision of reflective tools, such as learning logs or journals.

\section{ICT/digital competence of the telecollaborative teacher: I can ...}

22. choose the appropriate online communication tools (e.g. email, blogs, wikis, Skype) to fit both the everyday online practices of the students as well as the project's aims.

23. explain the use of chosen tools to students or can provide them with online or third-party support for learning how to use them.

24. organize and structure real-time student interaction taking into account the particular affordances and technicalities of synchronous tools such as videoconferencing, chat etc.

25. interact appropriately online with partner-teacher and, if necessary, with the participating students, attending to online communication norms (e.g. responding to emails in a timely manner, using appropriate register etc.)

26. organize the online exchange in a manner which protects students' safety and respects privacy issues related to students' work.

27. instruct learners on how to use online tools autonomously - tools which help them resolve language difficulties (e.g. online dictionaries, Google translator, multimedia authoring tools).

\section{Attitudes and beliefs of the telecollaborative teacher: I can show:}

28. a belief that culture plays an intrinsic role in foreign language education and online communication.

29. an openness to partner-teachers' alternative pedagogical beliefs and aims.

30. an interest in trying out new telecollaborative tasks and new online tools which may be proposed by students or partner-teachers.

31. a willingness to deal with new messages, texts and questions in contact classes or tutorials as they emerge during the online exchange.

32. a willingness to accept that the teacher is not the sole authority on the target culture and language.

33. interest in learning with students about new aspects of

L2 language use and cultural products and practices from their exchange partners. 
Appendix 3. Bold indicates the case of p-values less than 5\%

chi2 calculates and displays Pearson's chi-squared for the hypothesis that the rows and columns in a two-way table are independent.if p-value $<0.05$ we reject the nil hypothesis of independence.

\begin{tabular}{|c|c|c|c|}
\hline $\begin{array}{l}\text { Pearson } \\
\text { Chi-2 test }\end{array}$ & City & Gender & Qualification \\
\hline Q7 & $\operatorname{chi2}(12)=10.3965 \mathrm{Pr}=0.581$ & $\operatorname{chi2}(3)=1.1898 \quad \mathrm{Pr}=0.755$ & $\operatorname{chi} 2(6)=20.4337 \mathrm{Pr}=0.002$ \\
\hline Q8 & $\operatorname{chi} 2(12)=7.9960 \mathrm{Pr}=0.785$ & $\operatorname{chi2}(3)=2.9541 \quad \mathrm{Pr}=0.399$ & $\operatorname{chi2}(6)=27.1068 \mathrm{Pr}=0.000$ \\
\hline Q9 & $\operatorname{chi} 2(12)=13.9214 \mathrm{Pr}=0.306$ & $\operatorname{chi} 2(3)=5.7334 \mathrm{Pr}=0.125$ & $\operatorname{chi2}(6)=15.1151 \quad \operatorname{Pr}=0.019$ \\
\hline Q10 & $\operatorname{chi} 2(12)=18.9479 \mathrm{Pr}=0.090$ & $\operatorname{chi} 2(3)=1.2059 \mathrm{Pr}=0.752$ & $\operatorname{chi} 2(6)=11.1037 \quad \mathrm{Pr}=0.085$ \\
\hline Q11 & $\operatorname{chi2}(12)=4.8805 \mathrm{Pr}=0.962$ & $\operatorname{chi2}(3)=7.6806 \mathrm{Pr}=0.053$ & $\operatorname{chi2}(6)=11.1452 \mathrm{Pr}=0.084$ \\
\hline Q12 & $\operatorname{chi} 2(12)=21.9065 \mathrm{Pr}=0.039$ & $\operatorname{chi} 2(3)=6.4099 \mathrm{Pr}=0.093$ & $\operatorname{chi} 2(6)=21.0497 \quad \mathrm{Pr}=0.002$ \\
\hline Q13 & $\operatorname{chi} 2(12)=13.6635 \mathrm{Pr}=0.323$ & $\operatorname{chi2}(3)=13.2712 \operatorname{Pr}=0.004$ & $\operatorname{chi} 2(6)=8.7696 \quad \mathrm{Pr}=0.187$ \\
\hline Q14 & $\operatorname{chi2}(12)=8.2824 \mathrm{Pr}=0.763$ & $\operatorname{chi2}(3)=8.0516 \quad \mathrm{Pr}=0.045$ & $\operatorname{chi2}(6)=23.5125 \quad \mathrm{Pr}=0.001$ \\
\hline Q15 & $\operatorname{chi} 2(12)=7.2340 \mathrm{Pr}=0.842$ & $\operatorname{chi2}(3)=7.6985 \mathrm{Pr}=0.053$ & $\operatorname{chi} 2(6)=11.5810 \mathrm{Pr}=0.072$ \\
\hline Q16 & $\operatorname{chi} 2(12)=10.8674 \mathrm{Pr}=0.540$ & $\operatorname{chi} 2(3)=14.1530 \mathrm{Pr}=0.003$ & $\operatorname{chi2}(6)=20.8387 \mathrm{Pr}=0.002$ \\
\hline Q17 & $\operatorname{chi2}(12)=25.4138 \mathrm{Pr}=0.013$ & $\operatorname{chi2}(3)=16.9567 \quad \mathrm{Pr}=0.001$ & $\operatorname{chi2}(6)=12.6202 \mathrm{Pr}=0.049$ \\
\hline Q18 & $\operatorname{ch} 22(12)=12.3048 \mathrm{Pr}=0.422$ & $\operatorname{chi2} 2(3)=3.3361 \mathrm{Pr}=0.343$ & $\operatorname{chi} 2(6)=5.9964 \quad \mathrm{Pr}=0.424$ \\
\hline Q19 & $\operatorname{chi2}(12)=17.9058 \mathrm{Pr}=0.119$ & $\operatorname{chi2}(3)=8.6149 \operatorname{Pr}=0.035$ & $\operatorname{chi2}(6)=4.1123 \quad \operatorname{Pr}=0.661$ \\
\hline Q20 & $\operatorname{chi2}(12)=21.6166 \mathrm{Pr}=0.042$ & $\operatorname{chi} 2(3)=4.2970 \quad \mathrm{Pr}=0.231$ & $\operatorname{chi} 2(6)=7.3548 \quad \operatorname{Pr}=0.289$ \\
\hline Q21 & $\operatorname{chi2}(12)=11.5923 \mathrm{Pr}=0.479$ & $\operatorname{chi2}(3)=8.7265 \quad \mathrm{Pr}=0.033$ & $\operatorname{chi} 2(6)=8.9127 \quad \operatorname{Pr}=0.179$ \\
\hline Q22 & $\operatorname{chi} 2(12)=10.6638 \mathrm{Pr}=0.558$ & $\operatorname{chi2}(3)=8.1825 \mathrm{Pr}=0.042$ & $\operatorname{chi} 2(6)=6.4024 \quad \mathrm{Pr}=0.380$ \\
\hline Q23 & $\operatorname{chi2}(12)=15.4249 \mathrm{Pr}=0.219$ & $\operatorname{chi2}(3)=12.0245 \quad \operatorname{Pr}=0.007$ & $\operatorname{chi} 2(6)=7.0894 \quad \mathrm{Pr}=0.313$ \\
\hline Q24 & $\operatorname{chi} 2(12)=12.9667 \mathrm{Pr}=0.371$ & $\operatorname{chi2}(3)=13.1621 \quad \operatorname{Pr}=0.004$ & $\operatorname{chi} 2(6)=11.8313 \quad \mathrm{Pr}=0.066$ \\
\hline Q25 & $\begin{array}{cc}\operatorname{chi} 2(12)=9.7367 & \mathrm{Pr}=0.639\end{array}$ & $\operatorname{chi} 2(3)=7.9817 \mathrm{Pr}=0.046$ & $\operatorname{chi2}(6)=13.0378 \mathrm{Pr}=0.042$ \\
\hline Q26 & $\operatorname{chi2}(12)=4.8231 \quad \mathrm{Pr}=0.964$ & $\operatorname{chi2}(3)=11.4442 \quad \operatorname{Pr}=0.010$ & $\operatorname{chi} 2(6)=3.9297 \quad \mathrm{Pr}=0.686$ \\
\hline Q27 & $\operatorname{chi2}(12)=16.5403 \mathrm{Pr}=0.168$ & $\operatorname{chi2}(3)=9.5451 \quad \mathrm{Pr}=0.023$ & $\operatorname{chi} 2(6)=2.4018 \quad \mathrm{Pr}=0.879$ \\
\hline Q28 & $\operatorname{chi} 2(12)=4.8698 \mathrm{Pr}=0.962$ & $\operatorname{chi2} 2(3)=3.9223 \quad \mathrm{Pr}=0.270$ & $\operatorname{chi} 2(6)=9.5152 \quad \mathrm{Pr}=0.147$ \\
\hline Q29 & $\operatorname{chi2}(12)=5.3614 \mathrm{Pr}=0.945$ & $\operatorname{chi2}(3)=9.9360 \quad \mathrm{Pr}=0.019$ & $\operatorname{chi} 2(6)=17.4502 \mathrm{Pr}=0.008$ \\
\hline Q30 & $\operatorname{chi2}(12)=6.2331 \quad \mathrm{Pr}=0.904$ & $\operatorname{chi2}(3)=7.5475 \quad \mathrm{Pr}=0.056$ & $\operatorname{chi2}(6)=3.0259 \mathrm{Pr}=0.806$ \\
\hline Q31 & $\operatorname{chi2}(12)=11.1469 \mathrm{Pr}=0.516$ & $\operatorname{chi} 2(3)=5.8459 \quad \mathrm{Pr}=0.119$ & $\operatorname{chi} 2(6)=2.9426 \quad \mathrm{Pr}=0.816$ \\
\hline Q32 & $\operatorname{chi2}(12)=29.8537 \mathrm{Pr}=0.003$ & $\operatorname{chi2}(3)=9.2601 \quad \mathrm{Pr}=0.026$ & $\operatorname{chi} 2(6)=3.2513 \quad \mathrm{Pr}=0.777$ \\
\hline Q32 & $\operatorname{chi2}(12)=17.7532 \mathrm{Pr}=0.123$ & $\operatorname{chi} 2(3)=2.0440 \mathrm{Pr}=0.563$ & $\begin{array}{ll}\operatorname{chi} 2(6)=4.3473 & \operatorname{Pr}=0.630\end{array}$ \\
\hline
\end{tabular}

\section{Copyrights}

Copyright for this article is retained by the author(s), with first publication rights granted to the journal.

This is an open-access article distributed under the terms and conditions of the Creative Commons Attribution license (http://creativecommons.org/licenses/by/4.0/). 